Commentary

\title{
Urban Forms and Future Cities: A Commentary
}

\author{
Shlomo Angel
}

Marron Institute of Urban Management, New York University, New York, NY 10011, USA; E-Mail: sangel@stern.nyu.edu

Submitted: 18 January 2017 | Accepted: 20 January 2017 | Published: 20 February 2017

\begin{abstract}
The commentary reflects on the critical ways in which the proliferation of private property rights and local planning powers constrain and delimit the changes in the forms of cities that will be required in the coming years to ensure that they remain productive, inclusive, and sustainable. It argues that the effective management of the coming disruptions now require a shift of power from the private and the local to the metropolitan and the regional.
\end{abstract}

\section{Keywords}

arterial roads; conservation; eminent domain; metropolitan labor markets; Nimbyism; property rights; public works; smart cities; urban form; urban renewal

\section{Issue}

This commentary is part of the issue "Urban Forms and Future Cities", edited by Luca D'Acci (Erasmus University Rotterdam, The Netherlands), Tigran Haas (KTH Royal Institute of Technology, Sweden) and Ronita Bardhan (Indian Institute of Technology Bombay, India)

(C) 2017 by the author; licensee Cogitatio (Lisbon, Portugal). This article is licensed under a Creative Commons Attribution 4.0 International License (CC BY).

The forms of the cities of the future will be dictated by their past. Once streets and plot boundaries are laid out, they are very difficult to change. They are difficult to change because they demarcate and enshrine property rights.

When we look at the three-dimensional forms of cities we typically fail to see the underlying cadastral maps that chart the boundaries of individual plots. These invisible boundaries come to the fore only in times of change.

After the Great London Fire of 1666, Sir Christopher Wren quickly presented King Charles II a plan for rebuilding the city with modern street grids, wide avenues with open vistas, and public squares (see Figure 1).

But the King, fearful of an uprising, was reluctant to assume the power to confiscate the lands needed to implement the plans. The city was quickly rebuilt along the old property lines.

Whether it is the 1666 fire that destroyed London or the 2005 Hurricane Katrina that destroyed New Orleans, even great natural disasters cannot erase the old property boundaries that frustrate grand designs.

The property boundaries underlying our contemporary cities provide great protection for many and great barriers for many others. The future form of cities is en- tangled with our rather limited ability to change property boundaries.

Michael Heller's path-breaking book, The Gridlock Economy (2008), explores the consequences of allocating too many property rights to too many people. Too many property rights make it difficult, if not impossible, to change urban form.

Too many property rights make it difficult to widen streets; too many property rights make it difficult to straighten rail tracks so that trains can run faster; too many property rights make it difficult to assemble land for airport runways.

Most constitutions enshrine the right of government to acquire private property for public use with the payment of just compensation through what has come to be called 'eminent domain'. But eminent domain has proved to be quite cumbersome.

Surely, the application of eminent domain to the acquisition of lands for roads, railways, or other forms of public infrastructure such as ports, canals, or electrical grids, makes complete sense. Such lands could not be assembled otherwise.

Using eminent domain as a tool for changing urban form by assembling lands from private property owners and then giving it away to other private property owners 


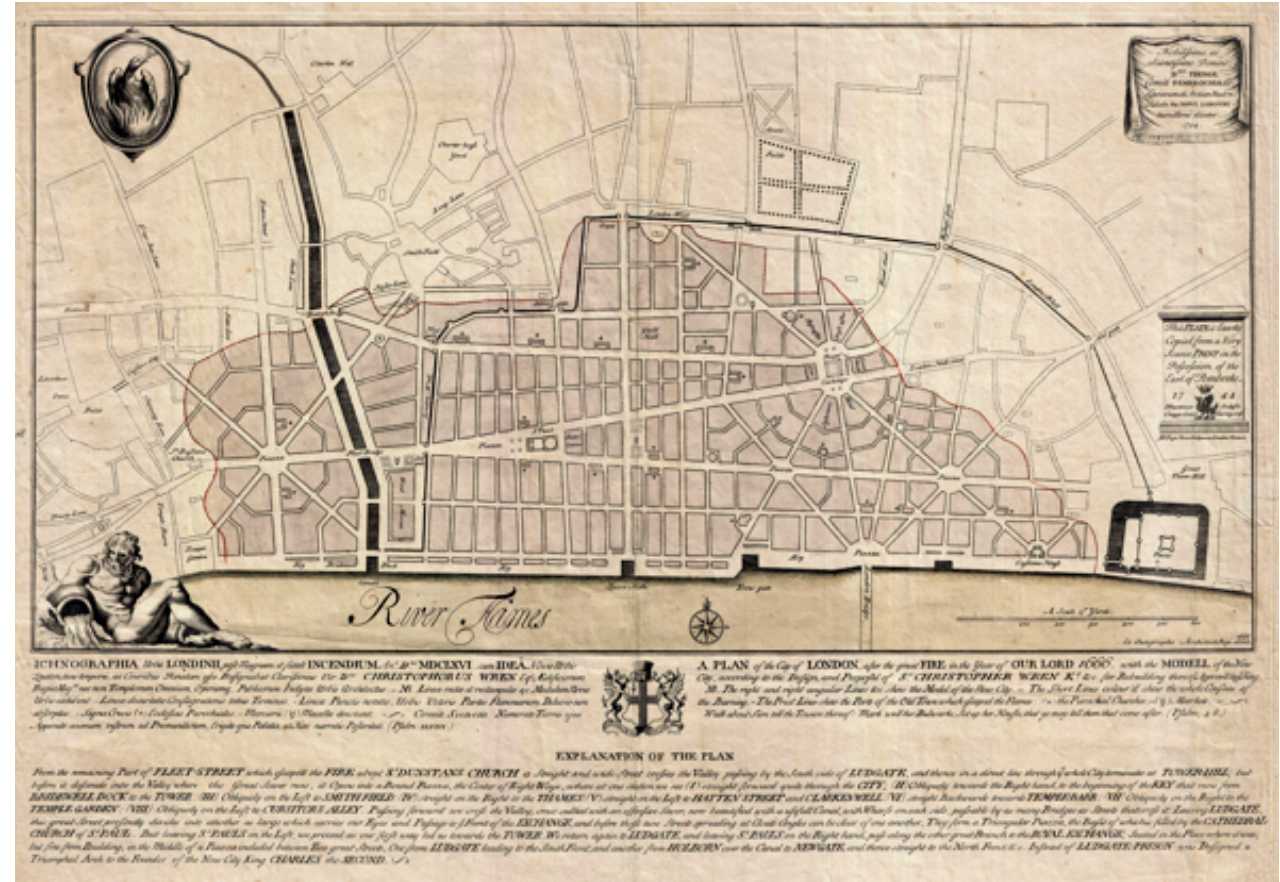

Figure 1. Sir Christopher Wren's plan, never realized, for rebuilding London after the Great Fire of 1666 (plan dated 1744).

is more problematic. In the U.S. it has led to a backlash against eminent domain.

Governments have also applied their eminent domain powers unconscionably for slum clearance, typically in the name of hygiene or crime prevention and most often to displace the poor by the not so poor. This practice must stop.

The settlements of the poor must be upgraded in situ, for the benefit of sitting residents, not to get rid of them. Attempts by great visionaries, like Le Corbusier, to clear the Left Bank in Paris and replace it by "towers in the park" must be resisted.

Still, in countries like China, where land ownership has been nationalized, acquiring land for infrastructure projects or clearing lands for large redevelopment projects by private interests is much easier than in countries like the U.S. or India.

This gives China an enormous advantage over the U.S. or India in executing large projects that require the assembly of large numbers of small plots, especially highways - and in the case of Chinese cities, ring roadsand new rail lines.

This advantage is translated into an economic advantage. Chinese cities, with twenty-first century infrastructure, can and will better compete in the global marketplace; Indian cities are falling behind and are unlikely to ever catch up.

Some large private projects, like college campuses, industrial parks, stadiums, or shopping malls have merit, but large projects, almost without exception are difficult to integrate to the existing fabric of cities and often remain "white elephants".

That said, the resistance of private property owners and local communities to allow for projects that may ben- efit larger metropolitan areas at their expense, no matter the compensation offered, limits future (and necessary) changes in urban form.

The cities of the future must be gradually renovated, or destroyed and rebuilt, as their economies and their cultures change. Living cities must remain responsive to the ever-changing needs, requirements, and preferences of their inhabitants.

Recent concerns with quality of life or with climate change have obscured the basic raison d'être of citiestheir productivity, an inclusive productivity that is, to an important extent, a function of their size.

Other things being equal, larger metropolitan areas are more productive than smaller ones. Their economies are more resilient and more efficient but, most of all, their advantages stem from their larger, integrated metropolitan labor markets.

In large, integrated labor markets, all workers have access to all jobs. Workers are able to find the best jobs and workplaces are able to find the best workers. That is why larger labor markets are more productive than smaller ones.

Jobs in U.S. cities have already decentralized. Only one-eighth of jobs are in Central Business districts and only one-eighth of jobs are in employment sub-centers. The rest are dispersed. Cities in other countries are likely to follow suit.

Fixed rail public transit or fixed route bus lines are not capable of serving commuters when both residences and workplaces are dispersed throughout metropolitan areas. We should not fixate on fixed route mass transit.

Commuters will need to continue to rely on doorto-door transport. The cities of the future may benefit from a new generation of driverless cars that use limited 
road space more efficiently and do not contribute to climate change.

Only one in twelve workers in U.S. metropolitan areas walks or bicycles to work. The rest take advantage of the entire metropolitan job market and travel quite far, but not too far, to their jobs (Figure 2). This pattern is not likely to change.

For large cities to have efficient labor markets, commuters need to traverse the city easily in all directions. Therefore, cities must have efficient networks of arterial roads or arterial railway systems that span their entire urban extents.

Think of the arterial road networks of cities, or more generally, the arterial infrastructure of cities-the main transport arteries, the main water, sewer and drainage arteries-as the glue that binds them together.

The evolution of a metropolitan network of arterial roads - wide roads that can carry public transport, and possibly bus rapid transport, trams, or light rail as wellrequires powers that are usually out of reach of typical municipal authorities.

The jurisdiction for a metropolitan transportation network is typically fragmented among smaller municipalities, making it almost impossible to plan for it, let alone overcome the resistance of property owners to implementing it on the ground.

Metropolitan areas that can put in place transport systems that make it possible for all workers to reach all jobs within a tolerable time-say 30 to 60 minuteswill have stronger, more productive and more inclusive economies.

Those that fail to do that will have weaker, less productive, and less inclusive economies. Those that favor localism of one kind or another rather than "metropolitanism" of one kind or another, will have to suffer the consequences.
And the kind of metropolitanism required is one that favors longer commutes to shorter ones, one that sees the metropolitan area as a whole as a single economic unit, not as a patchwork of utopian and unrealistic livework communities.

Small autarchic live-work communities are a thing of the past. Localism must give way to metropolitanism, and that can only happen when metropolitan power is strengthened at the expense of local power.

Otherwise, flourishing and self-righteous Nimbyism (Not In My Back Yard politics) of one kind or another will be able to prevent urban economies from staying competitive, productive, and inclusive by gradually evolving their forms.

The cities of the future may now need a new generation of Haussmann and Robert Moses types that can plan and implement large urban projects, carefully compromising local interests in the interest of metropolitan ones.

A new generation of large urban projects must be more sensitive and more reasonable, engaging in more modern forms of urban surgery than those of old, and respecting and giving voice, yet not surrendering, to local interests.

We need to re-envision the public good and we need to do it quickly. If the future power struggles to overcome the local resistance of the few for the greater benefit of the many are lost, again and again, we as a public will suffer the consequences.

The bright new "smart cities" planned and built at great expense from scratch at the edge of African cities, for example, far from the maddening crowd, are only expensive distractions. They reject existing cities, shying away from repairing them.

Large parts of cities need to be recycled and repaired-renovated or torn down and rebuilt anew-
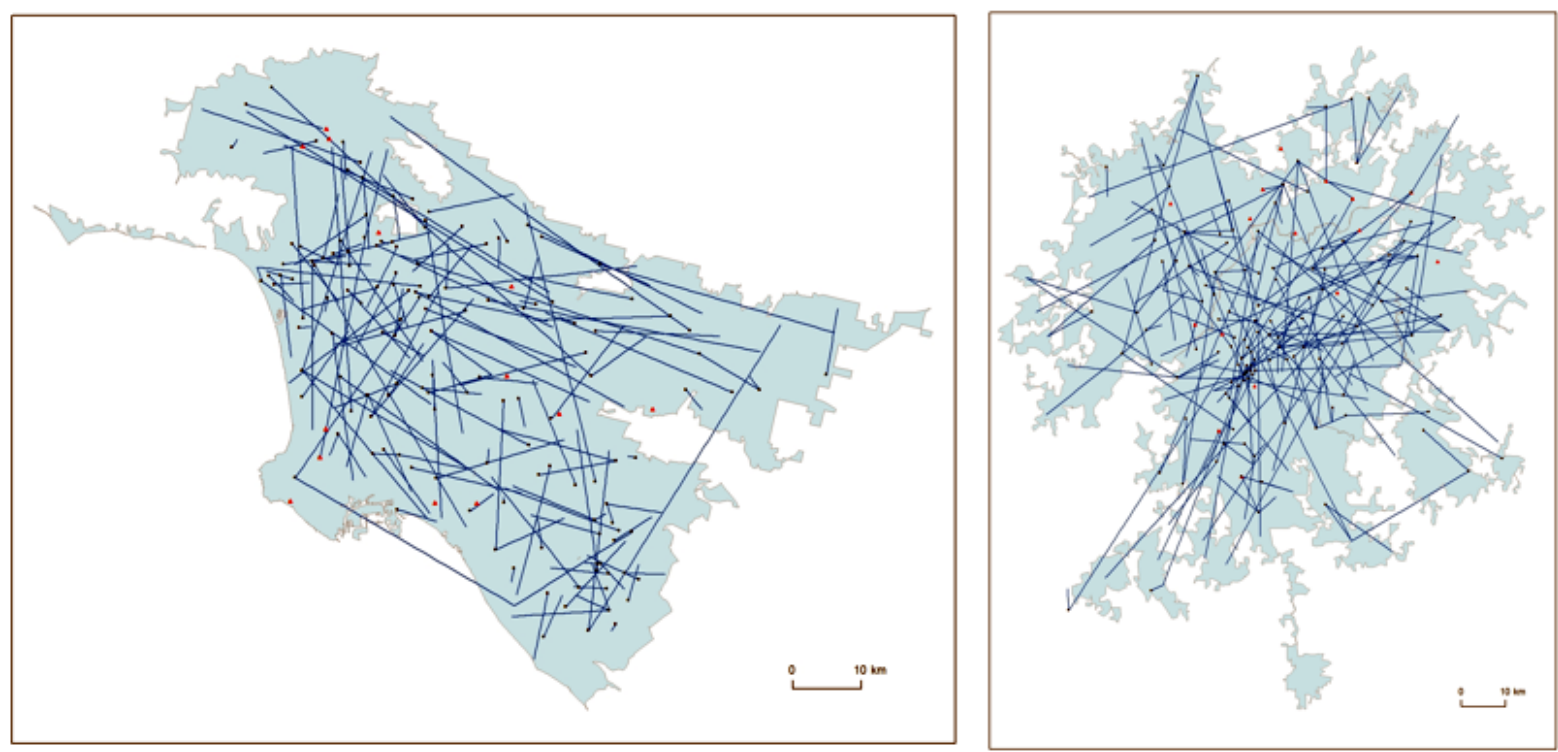

Figure 2. Los Angeles (left) and Atlanta (right) are integrated metropolitan labor markets: People live everywhere and work everywhere. Source: Angel \& Blei, 2016. 
for these cities to survive the coming economic, technological, social and cultural changes that are already becoming apparent.

The densification of cities, particularly the cities in more developed countries, is a key component of the urban agenda to address climate change. It too will require substantial recycling of urban neighborhoods.

Some parts of cities, their traditional neighborhoods in particular, can be retrofitted and improved, little by little, by upgrading their infrastructure and by sensitively increasing their densities along historical property lines.

That said, conservation and preservation have their limits too. Surely, the Chinese have gone too far in destroying the last vestiges of their traditional urban neighborhoods, let alone the ancient temples of their illustrious past.

More of them should have been preserved. We need old buildings to remind us of our past, to tie us down to our past. But those can be few and far between. In a large metropolitan area, they can number in the thousands, but not more.

The rest need to be transformed again and again and they do not need any special protection from their coming destruction or renovation. The great majority of buildings can be torn down and rebuilt as they have been in the past.

This process of recycling buildings, let alone entire neighborhoods, is disruptive. Disruption is indeed the essence of urban renewal, restoration, and revival. And it needs to be done right, with proper respect to sitting residents.

Its burden must be shared. Surely, it need not favor some at the expense of others. But disruption in cities is always local and, being local, it will always hurt specific places and particular people and leave others untouched.

All urban interventions that are aimed at improving the metropolitan area as a whole are local, so the few will and must suffer for the benefit of the many. That is a reality that must be confronted, again with the minimum pain possible.

A dollar lost, we already know, has a greater value than a dollar earned. There must be ways of compensating local residents correctly, but that said, a few property owners should not be able to stop an entire public from improving its lot.

In fact, communities and cities at large can benefit from a rule that says that if a supermajority agrees to a real estate deal, the rest must go along. Eminent domain need not resort to such a rule, but private developments should resort to it.

There should be a clear separation between public projects that require eminent domain for their correct implementation-roadways are a typical exampleand private projects that can choose between different locations.

Hospitals or college campuses, like residential developments or industrial estates, are private (or private-like) projects that can choose between different locations. Not so roads, rail lines, canals, or ports that must resort to eminent domain.

Such private or private-like developments should negotiate directly with locals, arrive at a reasonable deal with local representatives, and if such a deal is acceptable to a supermajority of locals, the rest should be mandated to go along.

This rule is already operational in some placesurban renewal projects in Israel are a good example-but needs to be accepted in many other places for cities to be able to accelerate their recycling processes in the future.

Zoning rules that have been promulgated to protect property values, not in the interest of health or safety, but in the interest of social or economic exclusion, should also be upended to accelerate the recycling of cities to meet new needs.

That said, the need to recycle cities is unlikely to be distributed evenly across world regions. It will need to be more pronounced in cities in more developed countries where urban population growth in future decades will be at a standstill.

Between 2015 and 2050, the urban population in more developed countries will only grow by 120 million. For every new urban resident in more developed countries, there will be 19 new urban residents in less developed ones.

Urbanization in the coming decades, understood as a growing share of the population residing in cities, will be largely an issue limited to less developed countries.

Cities in less developed countries will, on average, more than triple their land area between 2015 and 2050, while the land area in more developed countries is unlikely to double.

Cities that are going to triple or quadruple their land areas can plan for their orderly expansion by ensuring that lands converted to urban use contain arterial infrastructure grids and that future public open spaces are duly protected.

They can also adopt rules that ensure that all lands converted from rural to urban use reserve a third to forty percent of the land for streets, arterial roads, and public open spaces.

They can also adopt rules that minimize the size of city blocks while increasing four-way intersections, as well as rules that remove setbacks and allow buildings to reach their front property lines to facilitate the formation of streetscapes.

The key to improving future form of cities, especially cities that will need to house large numbers of poor people in less developed countries, is laying out streets in small blocks now, before development takes place.

Comás, a squatter invasion on the outskirts of Lima was laid out in the 1960 s by engineering student volunteers before it was occupied. It is now one of the most desirable residential neighborhoods in Lima (Figure 3).

The forms of the cities of the future, especially those in less developed countries, can be determined, in large 


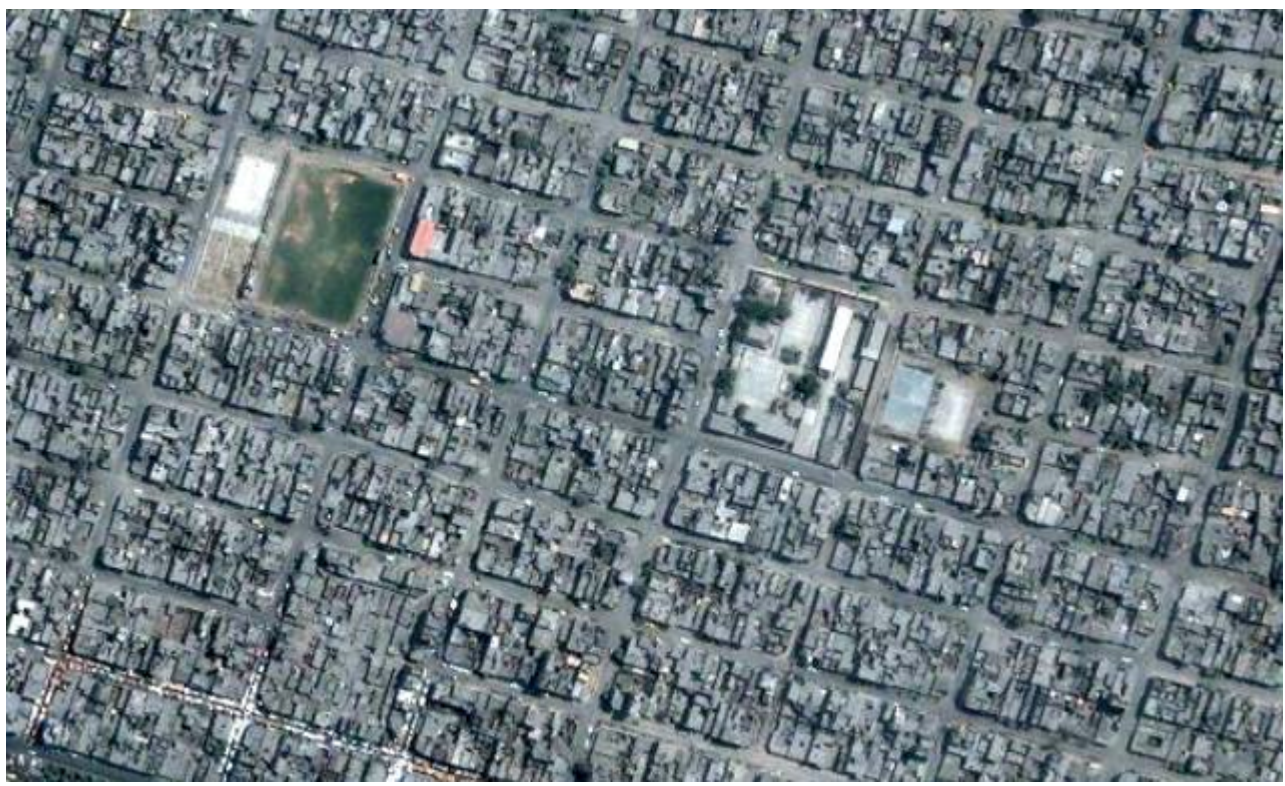

Figure 3. The streets in the Comás squatter community in Lima, Peru, are 10-meters-wide and take up $25 \%$ of the area. A $160 \mathrm{~m}^{2}$ house there now costs $\$ 180,000$. Source: Google Earth.

part, by acquiring the rights-of-way for arterial road grids now, by laying out streets now, and by acquiring lands for public open spaces now.

That said, the forms of the cities of the future will not be determined by grand designs but by a few public actions and a simple public regulatory regime that "set boundaries and provide support while relinquishing control".

Most of the designs that will determine the future forms of cities will be provided by market agents of one kind or another-be they households, firms, or civic actors-but these agents by themselves do not cities make.

There is an important role for all of us citizens, acting as a public, to lay out the infrastructure of cities-its public works - in advance, before any market agent can design, build, and thrive.

Evidence from the Atlas of Urban Expansion-2016 Edition (Angel, Lamson-Hall, Madrid, Blei, \& Parent, 2016) confirms we are still failing to make this happen: areas built after 1990 are more chaotic, less planned, and have less land for public works than before.

This will not do. For the cities of the future to be more productive, more inclusive, more sustainable, and more resilient, they need their public works, and they need them in place before real estate markets can thrive and flourish.
The form of the cities of the future, to the extent that we can envision it, will be determined, first and foremost, by public actions, pragmatic actions that can organize property rights, and that can finance and layout public works.

Neither the actions of the free market, nor utopian grand designs, can make that happen. Only a pragmatic approach to city building can, one that recognizes and harnesses the forces that propel cities into existence and let them thrive.

\section{References}

Angel, S., \& Blei, A. M. (2016). The productivity of American cities: How densification, relocation, and greater mobility sustain the productive advantage of larger U.S. metropolitan labor markets. Cities, 51, 36-51.

Angel, S., Lamson-Hall, P., Madrid, M., Blei, A. M., \& Parent, J. (2016). Atlas of urban expansion-2016 edition, volume 2: Blocks and roads. New York, Nairobi, Cambridge, MA: New York University, UN-Habitat, Lincoln Institute of Land Policy.

Heller, M. (2008). The gridlock economy: How too much ownership wrecks markets, stops innovation, and costs lives. New York: Basic Books.

\section{About the Author}

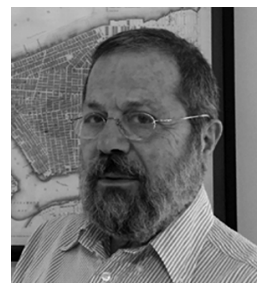

Shlomo (Solly) Angel is a Professor of City Planning and Director of the NYU Urban Expansion Program at the Marron Institute of Urban Management and the Stern School of Business at New York University. Angel holds an architecture degree and a doctorate in City and Regional Planning from the University of California at Berkeley. He is the author and co-author of numerous books and articles including A Pattern Language (1977), Housing Policy Matters (2000), Planet of Cities (2012) and Atlas of Urban Expansion-2016 Edition (2016). 